\title{
H)
}

Volume 17 Issue 3 Year: 2020

\section{Analysis of outdoor and indoor performance and recovery values after anaerobic performance ${ }^{1}$}

\author{
Tülin $\operatorname{Atan}^{2}$ \\ Şaban Ünver ${ }^{3}$ \\ İzzet İslamoğlu ${ }^{4}$ \\ Gül Çavuşoğlu ${ }^{5}$
}

\begin{abstract}
Research Problem/Aim: The objective of this study is to examine the anaerobic performance and recovery values after anaerobic performance in terms of outdoor or indoor performance.

Method: For this purpose, 30 male students studying at Faculty of Sports Sciences with an average age of 21.13 \pm 1.82 participated in the study voluntarily. Running-Based Anaerobic Sprint Test (RAST) was applied to the subjects twice with three days in-between as anaerobic exercise. Randomly chosen 15 subjects ran outdoors and the remaining 15 subjects ran indoors and their performance and recoveries were examined. Three days later, the subjects who ran outdoors three days ago ran indoors and those who ran indoors ran outdoors.

Findings: Anaerobic exercise performance was compared between indoor and outdoor area. Minimum power and average power values were found to be greater indoors than outdoors $(p<0.05$ ve $p<0.01)$, Peak power, fatigue index $(\mathrm{W} / \mathrm{sec})$ and fatigue index $(\%)$ values were not found to differ between indoor and outdoor areas $(\mathrm{p}>0.05)$. Before the anaerobic run, the athletes' resting lactic acid (LA) and heart rate (HR) values were taken, and then RAST test was applied. The subjects' recoveries were monitored for 10 minutes after the test. HR measurements were recorded at every minute of the recovery. On the 1st, 5th and 10th minutes of recovery, the subjects' blood LA levels were measured. No statistically significant difference was found between outdoor and indoor resting, 1st minute, 5th minute and 10th minute LA levels according to the results of statistical analyses $(\mathrm{p}>0.05)$. Resting and recovery HR values were also found not to differ between outdoor and indoor performance ( $\mathrm{p}>0.05)$.

Conclusions: It was concluded that outdoor and indoor performance did not influence recovery up to 10 minutes after anaerobic exercise. As a conclusion, some anaerobic exercise performance was better indoors than outdoors. Recovery after an anaerobic exercise was not found to differ between indoors and outdoors.
\end{abstract}

Keywords: Indoor-outdoor area; performance; recovery; anaerobic; lactic acid.

${ }^{1}$ This article is presented in the "14th International Sports Sciences Congress" in Antalya, Turkey (01-04 November 2016). ${ }^{2}$ Associate Professor, Ondokuz Mayis University, Faculty of Yasar Dogu Sport Science, takman@omu.edu.tr (iD) Orcid ID: 0000-0001-5660-8910

${ }^{3}$ Dr., Ondokuz Mayis University, Faculty of Yasar Dogu Sport Science, saban.unver@omu.edu.tr

(iD) Orcid ID: 0000-0001-7378-596X

${ }^{4}$ Research Assistant, Ondokuz Mayıs University, Faculty of Yasar Dogu Sport Science, izzetislamoglu@gmail.com (iD) Orcid ID: 0000-0001-5573-1423

${ }^{5}$ Assistant Professor, Ondokuz Mayis University, Faculty of Yasar Dogu Sport Science, gulcavusoglum@hotmail.com (iD) Orcid ID: $\underline{0000-0001-6520-2357}$ 
Atan, T., Ünver, S.., İslamoğlu, İ., \& Çavuşoğlu, G. (2020). Analysis of outdoor and indoor performance and recovery values after anaerobic performance. Journal of Human Sciences, 17(3), 840-846. doi:10.14687/jhs.v17i3.6015

\section{Introduction}

Training of athletes is a very long and complex process. There are many factors in the training efficiency of elite athletes. Athletes can be successful in sports by combining these factors (Arabac1, 2019, 15).

There are many sources of indoor air quality problems; these problems are caused by too much moisture, volatile organic chemicals emitted from mold, furniture and materials, chemicals resulting from improper use and storage of cleaning materials and training tools, inadequately planned and inadequate ventilation systems; indoor air quality problems can also result from diffuse result of asbestos or from construction materials during renovation work (Gullu, 2015, 5). Although hall sports contain various negativities such as lack of air circulation due to the areas where they are performed, those who do these sports, outdoor athletes encounter with intensity are less affected by many of the external factors such as cold, heat, rain, wind (Aslan ve Eyuboğlu, 2016). Adequate heating or cooling of enclosed spaces is one of the most important points. Inadequate heating of the hall, losing the flatness and stability of the floor may bring various health problems as well as affect the performance of the athletes negatively (Kuter ve Öztürk, 1999). Exercises in outdoor exercise parks contribute to individuals' protection from various diseases such as osteoporosis and type-2 diabetes besides their psychological benefits (Sixt et al., 2010, 116; Schmitt et al., 2009, 273).

Numerous studies have been conducted on recovery after exercise (Gill et al., 2006, 262; Ingram et al., 2009, 419; Atan et al., 2013, 75; Akgul and Cakmakc1, 2015, 147; Aslan et al., 2011, 98). For example, in Ingram et al. (2009)'s study, athletes were made to recover in three different ways after exercise. After exercise done every two weeks, recovery was followed with cold water, hot water or without any application and it was found that recovery with cold water was more beneficial. In another study about recovery, the effects of jogging and core training after supramaximal exercise were compared. It was found that jogging and core training after supramaximal exercise did not have different effects on recovery lactic acid levels; however, they were found to have different effects on heart rate. Core training was found to lower heart rate faster (Atan et al., 2013, 76). While LaCaille et al. (2004) found that outdoor running was determined to be less strenuous than indoor treadmill running (LaCaille et al. 2004). Ceci and Hassmén (1991) reported higher perceptions of exertion while running outside. Outdoor exercise is known to decrease negative affective states such as fatigue and stress (Harte and Eifert, 1995; Hansmann et al., 2007). Smith et al. (2001) compared the performance of $40 \mathrm{~km}$ of bicycles performed by 8 athletes with indoor and outdoor in area, and no significant difference was found between the two groups.

Recovery after exercise is very important for athletes. In our literature review, we did not come across any studies about indoor and outdoor recovery. In this study, recovery after anaerobic exercise was followed by checking lactic acid and heart rate. High lactic acid levels occur in the muscle after short-term maximum exercise, causing acidosis in both extra and intracellular compartments (Medbo and Sejersted, 1985, 99). Blood lactate reflects the level of anaerobic metabolism during an intense exercise. Peak levels of lactate in blood about five minutes after such an exercise shows that muscle and blood lactate are not balanced and that its concentration in the muscle is higher in the meantime. Removing lactate from blood depends on the level of training and metabolic speed to a great extent (Green and Dawson, 1993, 324). Athletes need improved speed and muscle strength and can be assumed to perform with limited improvement over the duration of the exercise for repeated maximum performances (Kafkas et al., 2018, 14).

Exercise performed in natural environments has been shown to have synergistic benefits relative to physical activity or nature alone (Mitchell, 2013, 132). In the study of Turner and Stevinson (2017), no significant differences between the outdoor and indoor conditions were observed at any point mid- or post-run. Exploratory moderator analyses also revealed no influence of the environmental conditions for specific sub-groups, including those with high nature-relatedness scores. Overall, their results suggest that natural and synthetic environments both have a positive influence on psychological well-being for regular runners regardless of the exercise intensity. In the 
Atan, T., Ünver, S.., İslamoğlu, İ., \& Çavuşoğlu, G. (2020). Analysis of outdoor and indoor performance and recovery values after anaerobic performance. Journal of Human Sciences, 17(3), 840-846. doi:10.14687/jhs.v17i3.6015

literature, it is seen that most of the comparisons between open and closed areas are made in terms of aerobic performance. In this study, recovery values after anaerobic performance was examined and it was determined whether the anaerobic performance differs according to the area in which it is performed. It can be said that the article will contribute to the literature.

\section{Purpose}

In this study, Running Based Anaerobic Sprint test was used to make the subjects get quickly and more tired and thus to follow the recovery clearly. The objective of this study is to examine recovery after indoor and outdoor exercise by analyzing lactic acid and heart rate.

\section{Methods}

\subsection{The place and time of the study}

The study took place at Sports Faculty of Ondokuz Mayis University in Samsun, between January 2016 and November 2016.

\subsection{Population and sample selection}

The population of the study consists of athletes in studying at the Faculty of Sports Sciences during the 2016-2017 education season. This study was conducted on 30 male athletes between the ages of 22 and 26 who were studying at the Faculty of Sports Sciences (age; 21.13 \pm 1.82 years, body weight; $69.72 \pm 6.79 \mathrm{~kg}$, body height; $174.72 \pm 4.76 \mathrm{~cm}$ ). Subjects are consists of licensed athletes dealing with a sports branch at least 10 years so the subjects have an experience of anaerobic exercises.

\subsection{Data collection}

Running Anaerobic Sprint Test (RAST) was applied to the subjects twice with three days inbetween. All the subjects were tested both indoors and outdoors. Outdoor sprints took place in athletics track; indoor sprints took place in indoor sports facility. On the first day, 15 of the subjects were subjected to RAST test outdoors, while the other 15 were subjected to the test indoors. Those who were tested outdoors on the first day were tested indoors on the second day while those who were tested indoors were tested outdoors. The subjects' performance values after indoor and outdoor RAST test were recorded.

\subsubsection{Application of the Test}

First, the athletes' rested LA and HR values were taken, and then they were subjected to RAST test. The subjects' recovery was followed for 10 minutes after the test. The subjects completed the recovery phase by walking. HR measures were recorded at every minute of recovery. Blood LA levels of subjects were measured on the first, fifth and tenth minutes of recovery.

\subsubsection{Running Anaerobic Sprint Test (RAST)}

This test was conducted with New Test-Power Timer 1.9.5. (Newtest, Oulu, Finland). In RAST test, athletes make 35-meter sprints six times successively with 10 seconds of break in-between sprints. The athlete starts the test with the first sprint. After 10 seconds of break, Power Timer gives a sound signal and the athlete makes the second sprint. The test is completed after the sixth sprint. Maximum power, average power, minimum power and fatigue index values are recorded. New Test-Power Timer device calculates and gives these parameters automatically.

\subsubsection{Lactic Acid Measurement}

Lactate concentration was measured with Lactate Plus Meter in mmol/L. Blood sample was taken from ear-lobe in accordance with sterilization rules. Ear-lobe was pierced with a Softclix make device which had a pen like needle on its tip. The blood sample taken was dripped on lactate test track. 13 seconds after this track was placed on Lactate Plus device, the lactic acid concentration in blood was found.

\subsubsection{Body Height/Body Weight Measurements}

Body heights were measured with one $\mathrm{cm}$ spaced body height measurement scale leaned on the wall. Body weights were measured on a floor scale with bare feet and a short on. 
Atan, T., Ünver, Ş., İslamoğlu, İ., \& Çavuşoğlu, G. (2020). Analysis of outdoor and indoor performance and recovery values after anaerobic performance. Journal of Human Sciences, 17(3), 840-846. doi:10.14687/jhs.v17i3.6015

\subsection{Research ethics}

In the study, official permission was first obtained from the Ethics Commission of the University of Ondokuz May1s, decision number 2015/132 on 12/03/2015 to collect the data and administer the scales.

\subsection{Evaluation of data}

As a result of the power analysis conducted to find out the number of subjects, it was found that the 30 was enough for the test to have $85 \%$ power. Arithmetic mean and standard deviations of the data obtained from the study were calculated and paired $t$ test was used to find whether there was difference between two trials. Statistical significance was taken as $p<0.05$. SPSS 21.0 version was used for the statistical analysis of the data.

\section{Results}

Table 1. Measurements taken during indoor and outdoor anaerobic exercise.

\begin{tabular}{|c|c|c|c|c|}
\hline RAST Parameters & Area & Mean & SD & $\mathrm{p}$ \\
\hline \multirow{2}{*}{ Peak Power (W) } & Indoor & 78.99 & 353.89 & \multirow{2}{*}{0.178} \\
\hline & Outdoor & 86.38 & 373.27 & \\
\hline \multirow{2}{*}{ Minimum Power (W) } & Indoor & 39.12 & 201.42 & \multirow{2}{*}{$0.015 *$} \\
\hline & Outdoor & 32.12 & 219.64 & \\
\hline \multirow{2}{*}{ Average Power (W) } & Indoor & 35.40 & 253.25 & \multirow{2}{*}{$0.000 * *$} \\
\hline & Outdoor & 44.30 & 280.03 & \\
\hline \multirow{2}{*}{$\begin{array}{c}\text { Fatigue Index } \\
(\mathrm{W} / \mathrm{sec})\end{array}$} & Indoor & 1.64 & 3.81 & \multirow{2}{*}{0.596} \\
\hline & Outdoor & 1.96 & 4.02 & \\
\hline \multirow{2}{*}{ Fatigue Index ( \%) } & Indoor & 16.77 & 51.56 & \multirow{2}{*}{0.175} \\
\hline & Outdoor & 16.62 & 56.99 & \\
\hline
\end{tabular}

Running Anaerobic Sprint Test performance values of athletes during outdoor and outdoor anaerobic exercise were compared in Table 1. Outdoor and indoor min power and average power values measured during anaerobic exercise were found to show statistically significant difference $(\mathrm{p}<0.05 ; \mathrm{p}<0.01)$. However, no statistically significant difference was found between outdoor and indoor peak power, fatigue index $(\mathrm{W} / \mathrm{sec})$, fatigue index $(\%)$ values $(\mathrm{p}>0.05)$.

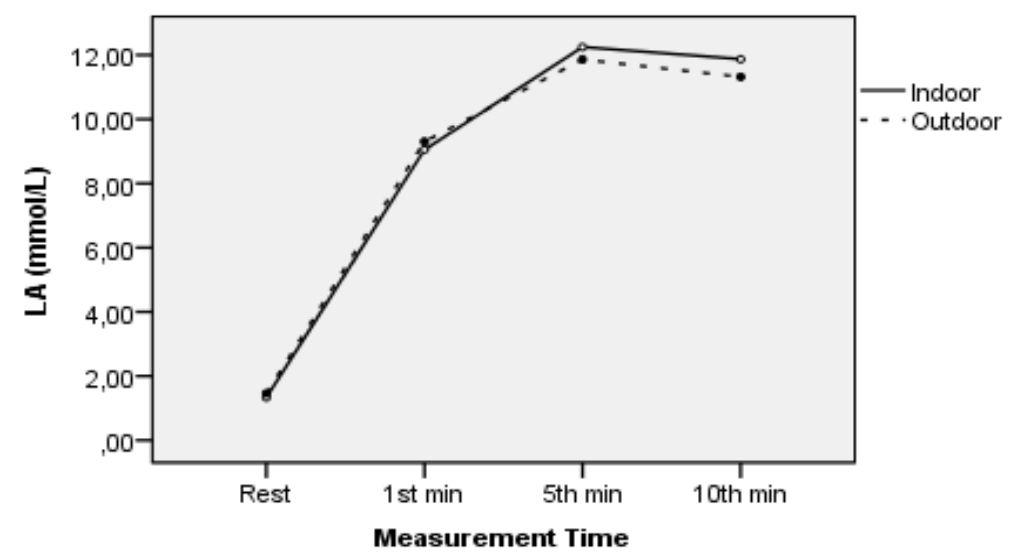

Figure 1. LA values before and after anaerobic exercise done outdoors and indoors.

Figure 1 shows the rested LA values and LA values 1 minute, 5 minutes, 10 minutes after exercise. Both outdoors and indoors, LA values reached the level of $12 \mathrm{mmol} / \mathrm{L}$ approximately five minutes after exercise. Again, LA values were around $11 \mathrm{mmol} / \mathrm{L}$ at 10 minutes after exercise 
Atan, T., Ünver, S., İslamoğlu, İ., \& Çavuşoğlu, G. (2020). Analysis of outdoor and indoor performance and recovery values after anaerobic performance. Journal of Human Sciences, 17(3), 840-846. doi:10.14687/jhs.v17i3.6015

both outdoors and indoors. No statistically significant difference was found between outdoor and indoor rested LA values and LA values 1 minute, 5 minutes, 10 minutes after exercise ( $p>0.05)$.

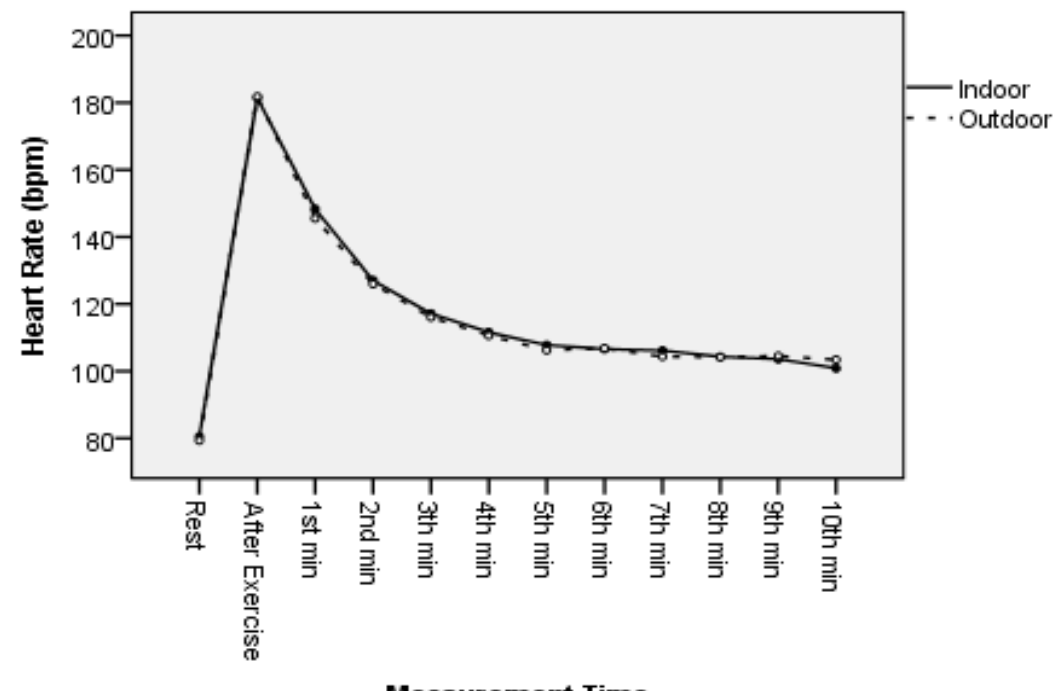

Figure 2. HR values before and after anaerobic exercise done outdoors and indoors.

Figure 2 shows athletes' rested HR values, HR values right after exercise, 1, 2, 3, 4, 5, 6, 7, 8, 9 and 10 minutes after exercise. Both outdoors and indoors, HR values reached the level of 180beat/min right after exercise. Again, HR values were found to decrease gradually after exercise both outdoors and indoors. No statistically significant difference was found between outdoor and indoor rested HR values and LA values 1 minute, 5 minutes, 10 minutes after exercise ( $p>0.05)$.

\section{Discussion}

This study compares the outdoor and indoor anaerobic exercise performance and recovery values of athletes. An anaerobic test was preferred in order to allow the subjects to have more fatigue faster and to follow the recovery more clearly. Minimum power and average power values measured during exercise were found to be higher indoors when compared with outdoors. There are studies in literature which support the results of the current study. In Smith et al. (2001)'s study, eight cyclists cycled $40 \mathrm{~km}$ three times outdoors and $40 \mathrm{~km}$ three times indoors. Average performance time in the trial that was conducted indoors was found to be better than average time in the trial that was conducted outdoors. In another study, 23 overweight women exercised three times a week for 12 weeks, body composition and $\mathrm{VO}_{2}$ max values of the women who exercised indoors were found to develop more when compared with the women who exercised outdoors (Lacharité-Lemieux and Dionne, 2016, 281).

No difference was found between outdoor and indoor peak power, fatigue index (W/sec), fatigue index $(\%)$ values in our study. The results of Brooks et al.'s study are in parallel with the results of our study.

The reason why there are studies in the literature that give results different from the results of our study is that these studies compare long-term outdoor exercises with indoor exercises. However, in our study the subjects had a one-time anaerobic exercise and the effects between outdoors and indoors was examined. Unlike the results of our study, there are also studies which show that outdoor performance is better than indoor performance. For example, Pasek et al. (2014) found that they have a positive effect on endurance levels and less signs of exhaustion in outdoor physical education classes. Lacharité-Lemieux et al. (2015) found that the women who had this exercise outdoors showed better response and adaptation to exercise than women who had this exercise indoors. Amelia and Pablo (2013) found that sprint time between 0-50 $\mathrm{m}$ indoors was longer than the sprint 
Atan, T., Ünver, S., İslamoğlu, İ., \& Çavuşoğlu, G. (2020). Analysis of outdoor and indoor performance and recovery values after anaerobic performance. Journal of Human Sciences, 17(3), 840-846. doi:10.14687/jhs.v17i3.6015

time outdoors both for men and for women. Similarly, they also stated that sprint time between 100$150 \mathrm{~m}$ was longer indoors (Amelia and Pablo, 2013, 87).

In our study, outdoor and indoor LA values were compared in order to analyze athletes' recovery values. Figure 1 shows the rested LA values and LA values 1 minute, 5 minutes, 10 minutes after exercise. Both outdoors and indoors, LA values reached the level of approximately $12 \mathrm{mmol} / \mathrm{L}$ five minutes after exercise. Again, LA values were around $11 \mathrm{mmol} / \mathrm{L}$ at 10 minutes after exercise both outdoors and indoors. No statistically significant difference was found between outdoors and indoors rested LA values and LA values 1 minute, 5 minutes, 10 minutes after exercise.

In a study by Nummela et al. (1997) which was conducted at the end of season with six male sprinters (three of them were 400 meter sprinters, while three of them were 400 meter hurdles, average age: 23, best average time: 50 seconds), after 400 meter sprint in an outdoor track, average peak blood lactate (fingertip) value was $15.4 \mathrm{Mm}$, while the average sprint time was 52.8 seconds.

In another study by Nummela et al. (1994) which was conducted with 10 male athletes most of whom were 400 meter sprinters or 400 meter hurdles (20-28 years of age, best average $400 \mathrm{~m}$ time: $51.24 \mathrm{sec}$ ), it was found that after 400 meter sprint in an outdoor track, average fingertip peak blood lactate level was $17.8 \mathrm{Mm}$, while the average sprint time was 54.4 seconds.

Outdoor and indoor HR values were also compared to analyze the athletes' recovery. Both outdoors and indoors, HR values reached the level of 180 beat/min right after exercise. Again, HR values were found to decrease gradually after exercise both outdoors and indoors. No statistical difference was found between outdoor and indoor rested HR values, HR values right after exercise, $1,2,3,4,5,6,7,8,9$ and 10 minutes after exercise ( $p>0.05$ ). Konarski and Strzelczyk (2009) researched whether heart rate and energy consumption differed between outdoors and indoors. They found that heart rate and energy consumption values between did not differ between area outdoor and indoor hockey games.

\section{Conclusions and recommendations}

The results of our study about LA and HR measured after supramaximal intensity load show that there are no differences between outdoor and indoor recovery. While there are a great number of studies about recovery after exercise in literature, no studies were found which examined recovery in terms of outdoor and indoor recovery. As a conclusion, it was found that some performance values during anaerobic exercise were better indoors. Recovery after exercise was found to be similar for indoors and outdoors. It can be said that the article will contribute to the literature. In future studies, a comprehensive study is proposed with increasing the number of samples or with athletes from different branches of sports.

Note: This study has been supported by Ondokuz Mayis University with the reference number PYO.YDS.1901.15.001

\section{References}

Akgul, M.S., \& Cakmakc1, O. (2015). The effect of hydrotherapy on recovery of soccer players. Spormetre the journal of physical education and sport sciences, 13(2), 143-150.

Amelia, F., \& Pablo, F. (2013). Differences in 200-m sprint running performance between outdoor and indoor venues. J Strength Cond Res, 27(1), 83-8.

Arabac1, R. (2019). Elite athlete training in the United States of America. Journal of Athletic Performance and Nutrition, 6(1), 12-28.

Aslan, A., Guvenc, A., Hazır, T., \& Acıkada, C. (2011). Recovery dynamics following high intensity exercise in young soccer players. Hacettepe J. of Sport Sciences, 22(3), 93-103.

Atan, T., Kabaday1, M., Elioz, M., Cilhoroz, B.T., \& Akyol, P. (2013). Effect of jogging and core training after supramaximal exercise on recovery. Turkish Journal of Sport and Exercise, 15(1), 73-79.

Brooks, D., Solway, S., Weinacht, K., Wang, D., \& Thomas, S. (2003). Investigated the performance between on an indoor and an outdoor 6-minute walk test. There was no significant effect of 
Atan, T., Ünver, S., İslamoğlu, İ., \& Çavuşoğlu, G. (2020). Analysis of outdoor and indoor performance and recovery values after anaerobic performance. Journal of Human Sciences, 17(3), 840-846. doi:10.14687/jhs.v17i3.6015

setting (indoors vs outdoors) on distance walked. Archives of Physical Medicineぬ Rehabilitation, 84(6), 873-876.

Gill, N.D., Beaven, C.M., \& Cook, C. (2006). Effectiveness of post-match recovery strategies in rugby players. BrJ Sports Med, 40, 260-263.

Green, S., \& Dawson, B. (1993). Measurement of anaerobic capacities in humans. Reviev article, Sports Med, 15(5), 312-327.

Gullu, G. (2015). Interaction of indoor air quality and health in primary schools. Internal environment quality seminars, Teskon, 1-7.

Ingram, J., Dawson, B., Goodman, C., Wallman, K., \& Beilby, J. (2009). Effect of water immersion methods on post-exercise recovery from simulated team sport exercise. Journal of Science and Medicine in Sport, 12, 417-421.

Kafkas, A., Çınarlı, F., \& Kafkas, M. (2018). The longitudinal development of endurance, sprint, agility, strength and jumping performance within college volleyball players. Journal of Athletic Performance and Nutrition, 5(2), 1-16.

Konarskı, J., \& Strzelczyk, R. (2009). Characterıstıcs of differences in energy expenditure and heart rate during indoor and outdoor field hockey matches. Studies in Physical Culture and Tournsm, 16(2).

Lacharité-Lemieux, M., Brunelle, J.P., \& Dionne, I.J. (2015). Adherence to exercise and affective responses: comparison between outdoor and indoor training. Menopause, 22(7), 731-740.

Lacharité-Lemieux, M., \& Dionne, I.J. (2016). Physiological responses to indoor versus outdoor training in postmenopausal women. J Aging Phys Act, 24(2), 275-83.

Medbo, J.I., \& Sejersted, O.D. (1985). Acid-base and electrolyte balance after exhausting exercise in endurance trained and sprint trained subjects. Acta Physiol Scand, 125, 97-109.

Mitchell, R. (2013). Is physical activity in natural environments better for mental health than physical activity in otherenvironments? Soc Sci Med. 91, 130-134.

Nummela, A., Rusco, H., \& Mero, A. (1994). EMG activities ground reaction forces during fatigued and nonfatigued sprinting. Med Sci Sports Exerc, 26(5), 605-609.

Nummela, A., Vuorimaa, T., \& Rusco, H. (1992). Change in force production, blood lactate and EMG activity in the $400 \mathrm{~m}$ sprint. J Sports Sci, 10, 217-228.

Pasek, M., Michalowska-Sawczyn, M., \& Nowak-Zaleska, A. (2014). Changes in maximal aerobic fitness and students' attitude towards physical effort during outdoor and indoor school lessons of Physical Education. Baltuc Journal of Health and Physical Activity, 6(1), 24-33.

Schmitt, N. M., Schmitt, J., \& Doren, M. (2009). The role of physical activity in the prevention of osteoporosis in postmenopausal women-an update. Maturitas, 63, 34-38.

Sixt, S., Beer, S., Blüher, M., Korff, N., Peschel, T., Sonnabend, M., Teupser, D., Thiery J., Adams, V., Schuler, G., \& Niebauer J. (2010). Long- but not short-term multifactorial intervention with focus on exercise training improves coronary endothelial dysfunction in diabetes mellitus type 2 and coronary artery disease. European Heart Journal, 31, 112-119.

Smith, M.F., Davison, R.C.R., Balmer, J., \& Bird, S.R. (2001). Reliability of mean power recorded during indoor and outdoor self-paced $40 \mathrm{~km}$ cycling time-trials. Int J Sports Med, 22(4), 270274.

Turner, T. L., \& Stevinson, C. (2017) Affective outcomes during and after high-intensity exercise in outdoor green and indoor gym settings. International Journal of Environmental Health Research, 27(2), 106-116. 